\title{
Bipolar membrane and interface materials for electrochemical energy systems
}

\author{
Ramato Ashu Tufa ${ }^{1, *}$, Marijn A. Blommaert ${ }^{2}$, Debabrata Chanda ${ }^{3}$, Qingfeng Li ${ }^{1}$, David A.
}

$$
\text { Vermaas }^{2, *}, \text { David Aili1, }{ }^{1}
$$

${ }^{1}$ Department of Energy Conversion and Storage, Technical University of Denmark, Building 310, 2800

Kgs. Lyngby, Denmark

${ }^{2}$ Department of Chemical Engineering, Delft University of Technology, 2629 HZ Delft, The Netherlands

${ }^{3}$ Henan Key Laboratory of Polyoxometalate Chemistry, Henan Engineering Research Center of Resource

\& Energy Recovery from Waste, College of Chemistry and Chemical, Engineering, Henan University,

Kaifeng 47504, PR China

Corresponding authors:

*E-mail: rastu@dtu.dk (Ramato Ashu Tufa)

D.A.Vermaas@tudelft.nl (David Vermaas)

larda@dtu.dk (David Aili) 


\section{I-V Characteristics of BPMs}

In a typical IV curve of a BPM (Fig. S1), a first plateau region is observed when salt ions are driven out of the bipolar interface resulting in the depletion of mobile ions at the interface. The current in this region is termed as the first limiting current $\left(i_{L 1}\right)$ which indicates the characteristic selectivity of the BPMs. A higher value of $i_{L 1}$ indicates poor selectivity or high co-ion leakage. The co-ion leakage or selectivity reflected by $i_{L 1}$ of a BPM is highly dependent on the properties of monopolar membrane layers such as thickness and charge density which will be discussed in section 3. Moreover, co-ion leakage across a BPM is directly related to the solution concentration and the diffusion coefficients in the membrane layers. A linear increase of current with voltage is observed above $i_{\mathrm{L} 1}$ attributed to the active water dissociation at the bipolar membrane interface.

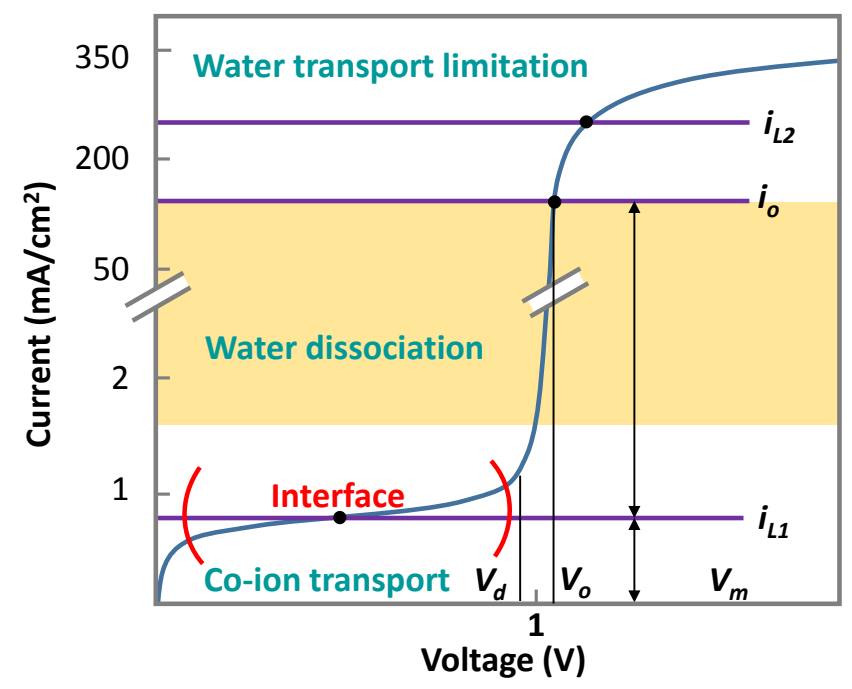

Figure S1. Typical I-V curve of bipolar membranes in a neutral salt solution. c) concentration profiles of the electrolytes species under steady-state current flow, and both diffusion and migration govern the transport of the ions.

\section{Summary of literature on reported materials for BPMs}

Selected literature on the materials for the BPM outer layers (CEL/AEL) and interface are summarized in Table 1. 
Table S1. Selected tailor-made bipolar membrane reported in the literature: materials for CEM, AEM, and interface layers.

\begin{tabular}{|c|c|c|c|c|c|}
\hline \multicolumn{3}{|c|}{ BPM components and materials } & \multirow{2}{*}{ Preparation method } & \multirow{2}{*}{ Characterization } & \multirow[t]{2}{*}{ Ref } \\
\hline$\overline{\text { CEL }}$ & AEM & Interface & & & \\
\hline S-PEEK & Psf & $\begin{array}{l}\text { Thin-film of S- } \\
\text { PEEK (SD80) and } \\
\text { P4VP }\end{array}$ & Solution casting & $\begin{array}{l}\text { I-V studies and } \\
\text { selectivity/co-ion } \\
\text { leakage }\end{array}$ & 1 \\
\hline $\begin{array}{l}\text { 2-HEMA/n-BA/(GMA)- } \\
\text { grafted with AA }\end{array}$ & $\begin{array}{l}\text { 2-HEMA/n-BA/(GMA)- } \\
\text { grafted with 4VP }\end{array}$ & - & $\begin{array}{l}\text { Solution } \\
\text { grafting polymerization }\end{array}$ & $\begin{array}{l}\text { Water dissociation } \\
\text { rate }\end{array}$ & 2 \\
\hline $\begin{array}{l}\text { PVDF-grafted with AA } \\
\text { or SVS }\end{array}$ & $\begin{array}{l}\text { PVDF-grafted with 4VP } \\
\text { or DMAEA }\end{array}$ & - & $\begin{array}{l}\text { Plasma-induced } \\
\text { grafting polymerization }\end{array}$ & $\begin{array}{l}\text { Water dissociation } \\
\text { rate }\end{array}$ & 2 \\
\hline SPEEK 1.4/PES & LbL modified FAA & $\begin{array}{l}\text { PEDOT:PSS and } \\
\text { PEI }\end{array}$ & $\begin{array}{l}\text { Solution casting/LBP } \\
\text { modification }\end{array}$ & $\begin{array}{l}\text { Water dissociation } \\
\text { rate and selectivity }\end{array}$ & 3 \\
\hline $\begin{array}{l}\text { ETFE film-grafted with } \\
\text { grafted with } \\
\text { Styrene (cross-linked } \\
\text { with divinylbenzene) } \\
\text { with sulphonic groups }\end{array}$ & $\begin{array}{l}\text { ETFE film-grafted with } \\
\text { grafted with } \\
\text { Styrene (cross-linked with } \\
\text { divinylbenzene) f with } \\
\text { quaternized ammonium } \\
\text { groups and a CEL }\end{array}$ & - & Radiation grafting & $\begin{array}{l}\text { I-V studies, water } \\
\text { dissociation rate and } \\
\text { selectivity }\end{array}$ & 5 \\
\hline
\end{tabular}




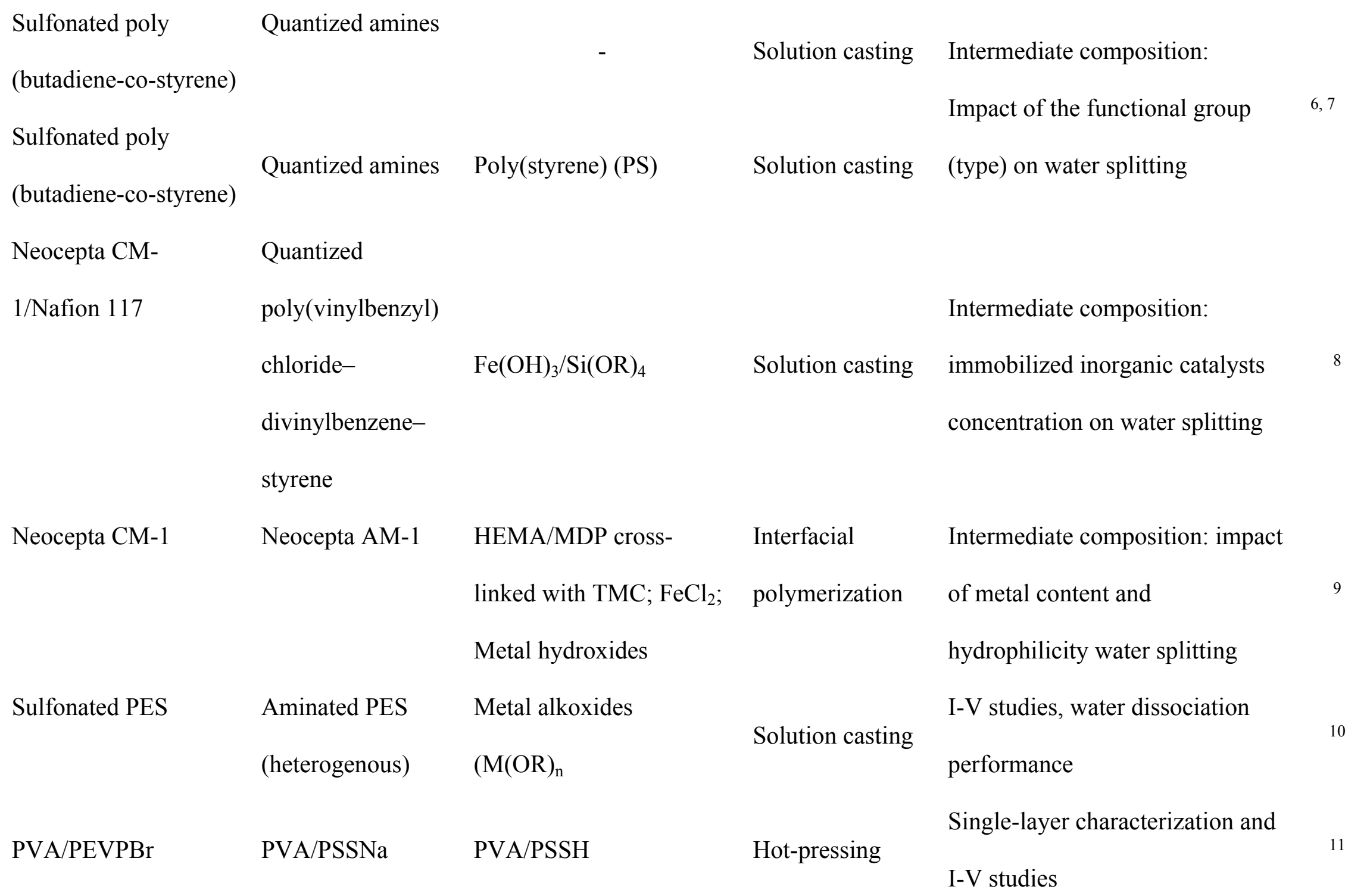




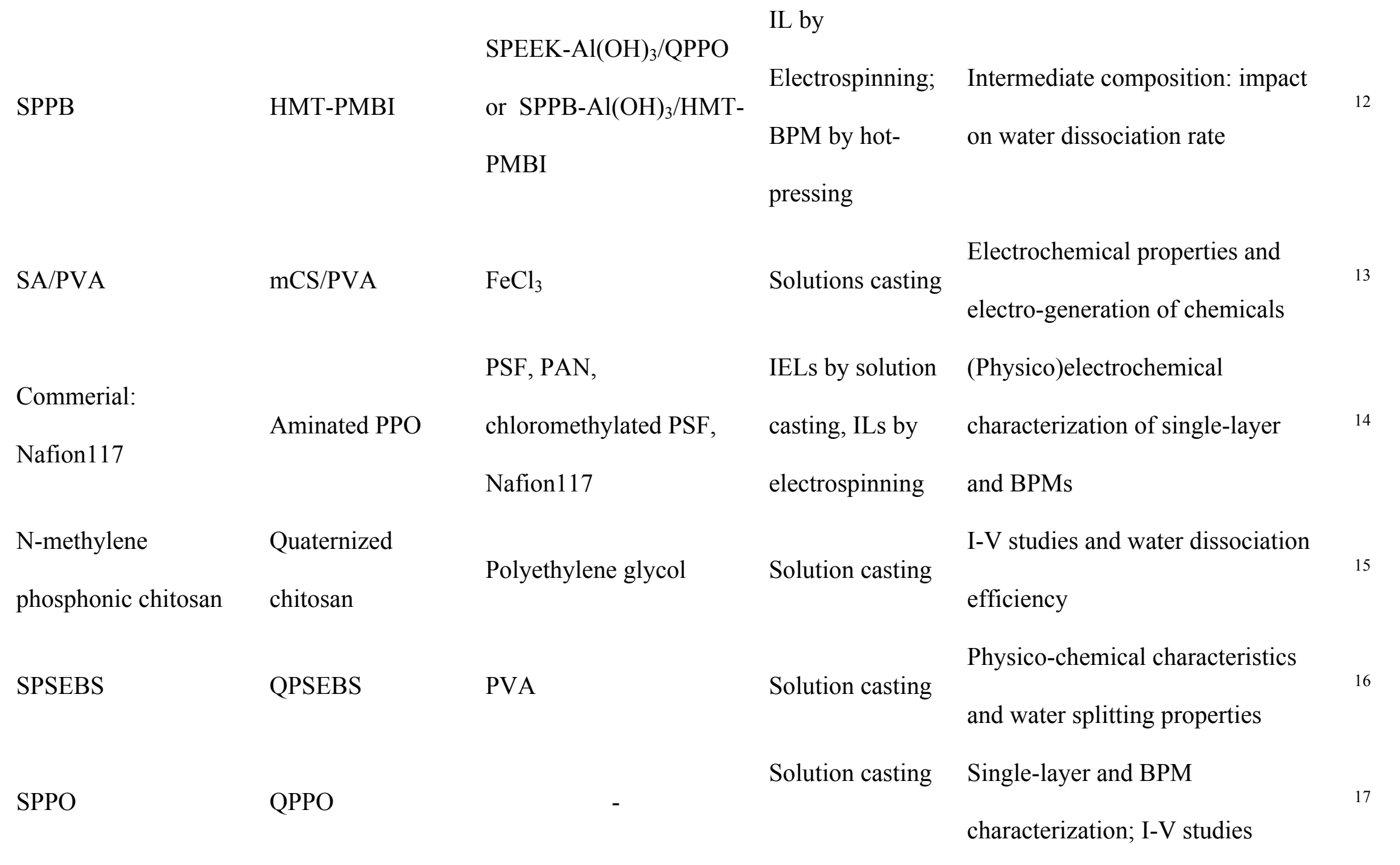




\begin{tabular}{|c|c|c|c|c|c|}
\hline QPPO & $\begin{array}{l}\text { PPO with different } \\
\text { amine groups }\end{array}$ & - & Solution casting & $\begin{array}{l}\text { Effect of type of functional } \\
\text { group; I-V studies }\end{array}$ & 18 \\
\hline SPPO & $\begin{array}{l}\text { Commercial: } \\
\text { Heterogeneous } \\
\text { quantized/PE binder }\end{array}$ & PAMAM or $\mathrm{AgCl}$ & Solution casting & $\begin{array}{l}\text { Impact of IL on water } \\
\text { dissociation: I-V and studies }\end{array}$ & 19,20 \\
\hline $\begin{array}{l}\text { Commercial: Nafion } \\
\text { NR-211 }\end{array}$ & $\begin{array}{l}\text { Commercial: } \\
\text { Neosepta AHA }\end{array}$ & $\mathrm{GO}$ & Spin-coating & $\begin{array}{l}\text { Physico-chemical } \\
\text { characterization and I-V studies }\end{array}$ & 21 \\
\hline SPPO & QPPO & $\begin{array}{l}\text { Graphene Oxide- } \\
\text { Polyaniline }\end{array}$ & $\begin{array}{l}\text { Layer-by-layer } \\
\text { casting }\end{array}$ & $\begin{array}{l}\text { Single-layer and BPM } \\
\text { characterization; IV } \\
\text { measurements; Impact of IL; ED } \\
\text { testing }\end{array}$ & 22 \\
\hline SPEEK & QPPO & $\begin{array}{l}\text { 3D/2D IL: } \\
\left(\mathrm{Al}(\mathrm{OH})_{3} \text { with or }\right. \\
\text { without } \\
\text { interpenetrating } \\
\text { SPEEK/QPPO }\end{array}$ & $\begin{array}{l}\text { Single and dual fiber } \\
\text { electrospinning }\end{array}$ & $\begin{array}{l}\text { Single-layer and BPM } \\
\text { characterization; IV studies; } \\
\text { Impact of IL on water } \\
\text { dissociation }\end{array}$ & 23 \\
\hline
\end{tabular}


Solution casting

Physical characterization; I-V and

\section{EIS studies}

I-V and EIS studies; thickness of

$\begin{array}{ll}\text { CuTsPc-SA } & \text { CuTAPc-CS } \\ \text { SPPO } & \text { QPPO }\end{array}$

QPPO

QPPO

SPPO

PVA-Fe-SA

Sulphonated

PVA-GA-CS

Commercial:

Heterogeneous anion-

polytetrafluorethylene SPSU

exchange membrane CHI-PSU

(MA-41)

Commercial:

Commercial:

Hetermergiedis anion-

exengtized membranes

(quaternary

ammonium-type)
FqO3๋: Fe-MIL- Solution casting Solution casting

$$
101-\mathrm{NH}_{2}
$$

PEG

Polyacrylamide

\section{Electrospinning/hot}

pressiagation-induced grafting; solution

casting

$\mathrm{FeCl}_{3}$

Solution casting

\section{Solution casting}

Solution casting

Solution casting

$\mathrm{FeCl}_{3} /$ palygorskite Solution casting Poly(acrylonitril Solution casting

e) (PAN)

$$
\mathrm{Nb}_{3} \mathrm{Ga}, \mathrm{C}_{60} \text {, or }
$$

Electrochemical properties; I-V and

the IL and impact on water

EIS studies

dissociation

Physical characterization; I-V

studies; water splitting and co-ion

leakggggle and BPM characterization;

(electro)pthdisicochemical

Electrochemical generation

Single-layer and BPM

(electro)Physicochemical

characterization; IV studies

characterization; I-V studies and

power density in RED application

I-V studies in different liquid IV and EIS studies; Impact of IL electrolytes

on water splitting performance; Single and bipolar membrane

Interface stability

characterization; I-V studies;

Enhanced the water and methanol 
poly(divinylbenzene-

Commercial: Nafion co-styrene)

Commercial:

Neosepta ${ }^{\circledR}$ CM-1

Neocepta CMX, or
Commercial:

tailored SPEEK-PES

poly(divinylbenzene-

PBI

co-styrene)

Poly(GMA-DVB-

$\mathrm{PVC}_{34}-\mathrm{Py}$

Commercial:

Neocepta AM-2,

R4030, or tailored

A-Psf

$\mathrm{Fe}(\mathrm{OH})_{3}$,

P4VP, SPEEK,

PAA, PFS

$\mathrm{Fe}(\mathrm{OH})_{3}$

PAA, PFS

Commercial: Nafion A-PPO

A-PPO
$\mathrm{TiO}_{2}$

$-$

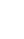

GO/PDDA: splitting effect

Manual lamination Physical and electrochemical

39

Single and BPM characterization; I-

V studies; Water dissociation

capacity

Solution casting- $\quad$ Single and BPM characterization; I-

evaporation

V studies; Impact of IL functionality

technique/IL by

electrodeposition

and water content on BPM

resistance; Stability

Solution

casting/LBL

2D/3D junctions

assembly
Physicochemical characterization; I$\mathrm{V}$ ans EIS studies; relating electric

field and interfacial catalysis or water dissociation rate 
NR-211

PVA/AP2

Commercial: Nafion

117

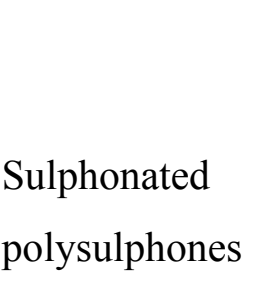

$$
\text { PSQA }
$$$$
\text { GO, GP, CNTs }
$$

PVA/PAAm

PVA

Quantized

polysulphones
Manual lamination

Membrane potential in the

Spin coating/Solution

Phosphorylated graphene

oxide (PGO) or quaternized

graphene oxide (QGO)
Solution casting

Layer-by-layer

casting dialysis system

I-V studies; the impact of IL

composition and thickness on

water splitting

Physicochemical

characteristics and ED

testing

I-V studies and water splitting 


\section{References}

1. Balster, J.; Sumbharaju, R.; Srikantharajah, S.; Pünt, I.; Stamatialis, D. F.; Jordan, V.; Wessling, M., Asymmetric bipolar membrane: A tool to improve product purity. Journal of Membrane Science 2007, 287 (2), 246256.

2. Hsueh, C.-L.; Peng, Y.-J.; Wang, C.-C.; Chen, C.-Y., Bipolar membrane prepared by grafting and plasma polymerization. Journal of Membrane Science 2003, 219 (1), 1-13.

3. Abdu, S.; Sricharoen, K.; Wong, J. E.; Muljadi, E. S.; Melin, T.; Wessling, M., Catalytic Polyelectrolyte Multilayers at the Bipolar Membrane Interface. ACS Applied Materials \& Interfaces 2013, 5 (21), $10445-10455$.

4. Xue, Y.; Wang, N.; Huang, C.; Cheng, Y.; Xu, T., Catalytic water dissociation at the intermediate layer of a bipolar membrane: The role of carboxylated Boltorn ${ }^{\circledR}$ H30. Journal of Membrane Science 2009, 344 (1), 129 135 .

5. El Moussaoui, R.; Pourcelly, G.; Maeck, M.; Hurwitz, H. D.; Gavach, C., Co-ion leakage through bipolar membranes Influence on I-V responses and water-splitting efficiency. Journal of Membrane Science 1994, 90 (3), 283-292.

6. Shimizu, K.; Tanioka, A., Effect of interface structure and amino groups on water splitting and rectification effects in bipolar membranes. Polymer 1997, 38 (21), 5441-5446.

7. Hosono, T.; Tanioka, A., Effect of polymer composition in intermediate layer on water splitting in bipolar membranes. Polymer 1998, 39 (18), 4199-4204.

8. Kang, M.-S.; Choi, Y.-J.; Moon, S.-H., Effects of inorganic substances on water splitting in ion-exchange membranes: II. Optimal contents of inorganic substances in preparing bipolar membranes. Journal of Colloid and Interface Science 2004, 273 (2), 533-539.

9. Kang, M.-S.; Tanioka, A.; Moon, S.-H., Effects of interface hydrophilicity and metallic compounds on water-splitting efficiency in bipolar membranes. Korean Journal of Chemical Engineering 2002, 19 (1), 99-106.

10. Rajesh, A. M.; Chakrabarty, T.; Prakash, S.; Shahi, V. K., Effects of metal alkoxides on electro-assisted water dissociation across bipolar membranes. Electrochimica Acta 2012, 66, 325-331.

11. Lebrun, L.; Da Silva, E.; Pourcelly, G.; Métayer, M., Elaboration and characterisation of ion-exchange films used in the fabrication of bipolar membranes. Journal of Membrane Science 2003, 227 (1), 95-111.

12. Hohenadel, A.; Powers, D.; Wycisk, R.; Adamski, M.; Pintauro, P.; Holdcroft, S., Electrochemical Characterization of Hydrocarbon Bipolar Membranes with Varying Junction Morphology. ACS Applied Energy Materials 2019, 2 (9), 6817-6824.

13. Wang, Y.-H.; Chen, R.-Y.; Zheng, X.; Ma, X.-L.; Chen, Z., Electro-generation of 3-methyl-2formylaminopyridine using a bipolar membrane as separator. Journal of Applied Electrochemistry 2009, 39 (8), 1237-1242.

14. McClure, J. P.; Grew, K. N.; Chu, D., Experimental Development of Alkaline and Acid-Alkaline Bipolar Membrane Electrolytes. ECS Transactions 2015, 69 (18), 35-44.

15. Rajesh, A. M.; Kumar, M.; Shahi, V. K., Functionalized biopolymer based bipolar membrane with poly ethylene glycol interfacial layer for improved water splitting. Journal of Membrane Science 2011, 372 (1), $249-257$.

16. Venugopal, K.; Dharmalingam, S., Fundamental studies on a new series of SPSEBS-PVA-QPSEBS bipolar membrane: Membrane preparation and characterization. Journal of Applied Polymer Science 2013, 127 (6), 49834990.

17. Xu, T.; Yang, W., Fundamental studies on a novel series of bipolar membranes prepared from poly (2, 6dimethyl-1, 4-phenylene oxide)(PPO): I. Effect of anion exchange layers on I-V curves of bipolar membranes.

Journal of Membrane Science 2004, 238 (1-2), 123-129.

18. Xu, T.; Fu, R.; Yang, W.; Xue, Y., Fundamental studies on a novel series of bipolar membranes prepared from poly(2,6-dimethyl-1,4-phenylene oxide) (PPO): II. Effect of functional group type of anion-exchange layers on I-V curves of bipolar membranes. Journal of Membrane Science 2006, 279 (1), 282-290.

19. Fu, R.-Q.; Xu, T.-W.; Cheng, Y.-Y.; Yang, W.-H.; Pan, Z.-X., Fundamental studies on the intermediate layer of a bipolar membrane: Part III. Effect of starburst dendrimer PAMAM on water dissociation at the interface of a bipolar membrane. Journal of Membrane Science 2004, 240 (1), 141-147.

20. Xue, Y.-H.; Fu, R.-Q.; Fu, Y.-X.; Xu, T.-W., Fundamental studies on the intermediate layer of a bipolar membrane: V. Effect of silver halide and its dope in gelatin on water dissociation at the interface of a bipolar membrane. Journal of Colloid and Interface Science 2006, 298 (1), 313-320.

21. McDonald, M. B.; Freund, M. S., Graphene Oxide as a Water Dissociation Catalyst in the Bipolar Membrane Interfacial Layer. ACS Applied Materials \& Interfaces 2014, 6 (16), 13790-13797. 
22. Manohar, M.; Shahi, V. K., Graphene Oxide-Polyaniline as a Water Dissociation Catalyst in the Interfacial Layer of Bipolar Membrane for Energy-Saving Production of Carboxylic Acids from Carboxylates by Electrodialysis. ACS Sustainable Chemistry \& Engineering 2018, 6 (3), 3463-3471.

23. Zhang, W.; Miao, M.; Pan, J.; Sotto, A.; Shen, J.; Gao, C.; Van der Bruggen, B.; Engineering, Process economic evaluation of resource valorization of seawater concentrate by membrane technology. ACS Sustainable Chemistry \& Engineering 2017, 5 (7), 5820-5830.

24. Wang, Q.; Wu, B.; Jiang, C.; Wang, Y.; Xu, T., Improving the water dissociation efficiency in a bipolar membrane with amino-functionalized MIL-101. Journal of Membrane Science 2017, 524, 370-376.

25. Chen, G.; Xu, T.; Liu, J., Irradiation-induced grafting of polyacrylamide onto the sulphonated poly(2,6dimethyl-1,4-phenylene oxide) (SPPO) films as well as its use as a catalytical layer in a bipolar membrane. Journal of Applied Polymer Science 2008, 109 (3), 1447-1453.

26. Zabolotsky, V.; Utin, S.; Bespalov, A.; Strelkov, V., Modification of asymmetric bipolar membranes by functionalized hyperbranched polymers and their investigation during $\mathrm{pH}$ correction of diluted electrolytes solutions by electrodialysis. Journal of Membrane Science 2015, 494, 188-195.

27. Peng, F.; Peng, S.; Huang, C.; Xu, T., Modifying bipolar membranes with palygorskite and $\mathrm{FeCl3}$. Journal of Membrane Science 2008, 322 (1), 122-127.

28. Chen, R.; Hu, Y.; Chen, Z.; Chen, X.; Zheng, X., Preparation and characterization of bipolar membranes modified using photocatalyst nano- $\mathrm{TiO}_{2}$ and nano-ZnO. Journal of Applied Polymer Science 2011, 122 (2), 12451250 .

29. Shi, S.; Pan, Y.; Lu, B.; Shen, C.; Zheng, G.; Liu, C., Preparation and Characterization of a Bipolar Membrane Modified by Copper Phthalocyanine 16-Carboxylic Acid and Acetyl Ferrocene. Journal of Macromolecular Science, Part B 2014, 53 (8), 1431-1441.

30. Chen, R.-Y.; Chen, Z.; Zheng, X.; Chen, X.; Wu, S.-Y., Preparation and characterization of mSA/mCS bipolar membranes modified by CuTsPc and CuTAPc. Journal of Membrane Science 2010, 355 (1), 1-6.

31. Pan, J.; Hou, L.; Wang, Q.; He, Y.; Wu, L.; Mondal, A. N.; Xu, T., Preparation of bipolar membranes by electrospinning. Materials Chemistry and Physics 2017, 186, 484-491.

32. Xu, C.-X.; Chen, R.-Y.; Zheng, X.; Chen, X.; Chen, Z., Preparation of PVA-GA-CS/PVA-Fe-SA bipolar membrane and its application in electro-generation of 2,2-dimethyl-3-hydroxypropionic acid. Journal of Membrane Science 2008, 307 (2), 218-224.

33. Pretz, J.; Staude, E., Reverse electrodialysis (RED) with bipolar membranes, an energy storage system. Berichte der Bunsengesellschaft für physikalische Chemie 1998, 102 (4), 676-685.

34. Chou, T.-J.; Tanioka, A., Current-Voltage Curves of Composite Bipolar Membrane in Alcohol-Water Solutions. The Journal of Physical Chemistry B 1998, 102 (40), 7866-7870.

35. Chou, T. J.; Hong, P. D.; Tanioka, A., Study on current-voltage curves of composite bipolar membrane for water and methanol solutions. Journal of Membrane Science 2000, 75 (13), 1597-1604.

36. Jeevananda, T.; Yeon, K.-H.; Moon, S.-H., Synthesis and characterization of bipolar membrane using pyridine functionalized anion exchange layer. Journal of Membrane Science 2006, 283 (1), 201-208.

37. Balster, J.; Srinkantharajah, S.; Sumbharaju, R.; Pünt, I.; Lammertink, R. G. H.; Stamatialis, D. F.; Wessling, M., Tailoring the interface layer of the bipolar membrane. Journal of Membrane Science 2010, 365 (1), 389-398.

38. Yan, Z.; Zhu, L.; Li, Y. C.; Wycisk, R. J.; Pintauro, P. N.; Hickner, M. A.; Mallouk, T. E., The balance of electric field and interfacial catalysis in promoting water dissociation in bipolar membranes. Energy \& Environmental Science 2018, 11 (8), 2235-2245.

39. Chabi, S.; Wright, A. G.; Holdcroft, S.; Freund, M. S., Transparent Bipolar Membrane for Water Splitting Applications. ACS Applied Materials \& Interfaces 2017, 9 (32), 26749-26755.

40. Higa, M.; Kira, A., Transport of Ions across Bipolar Membranes. 1. Theoretical and Experimental Examination of the Membrane Potential of $\mathrm{KCl}$ Solutions. The Journal of Physical Chemistry 1995, 99 (14), 50895093.

41. Chen, Y.; Martínez, R. J.; Gervasio, D.; Baygents, J. C.; Farrell, J., Water splitting promoted by electronically conducting interlayer material in bipolar membranes. Journal of Applied Electrochemistry 2020, 50 (1), 33-40.

42. Venugopal, K.; Dharmalingam, S., Desalination efficiency of a novel bipolar membrane based on functionalized polysulfone. Desalination 2012, 296, 37-45. 